\title{
Intracranial and orbital aspergillosis in immunocompetent patient
}

\author{
Josie Naomi lyeyasu', Fabiano Reis², \\ Albina Messias Altemani ${ }^{3}$, Keila Monteiro de Carvalho ${ }^{4}$
}

A 32-year old woman presented with headache and diplopia for two years. She does not have immunologicic and rheumathic diseases, neither hypertension, diabetes and HIV.

Neurological examination showed absence of abduction of the right eye.

This is a pseudotumoral lesion due to aspergillosis, with a solid intraconal lesion
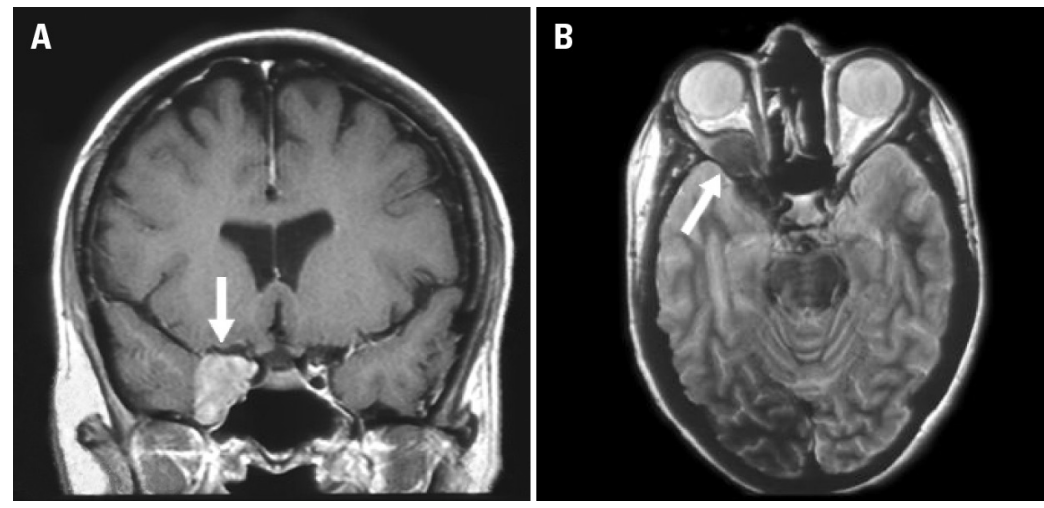

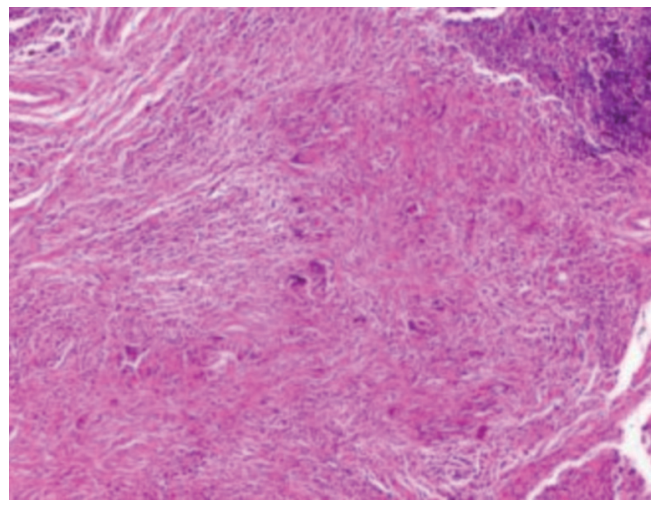

Fig 2. Granulomatous inflammation in orbital tissues showing central necrosis and numerous Langhanstype giant-cells $(\mathrm{HE} \times 200)$. going intracranially to the cavernous sinus (Fig $1 \mathrm{~A}$ and $1 \mathrm{~B}$ ). Hypointensity on T2 MRI may suggest the possibility of inflammatory etiology (particularly fungal infections). Aspergillosis is not usually observed in immunocompetent patients.

The patient was submitted to subtotal resection of the lesion (Fig 2 and 3). She received corticosteroids and oral itraconazole, with favorable evolution.

Fig 1. [A] Enhanced coronal T1- weighted imaging showing a right parasselar lesion (with extension to the cavernous sinus), with intense homogeneous enhancement. [B] Axial T2: hypointense intraconal lesion with intracranial extension.

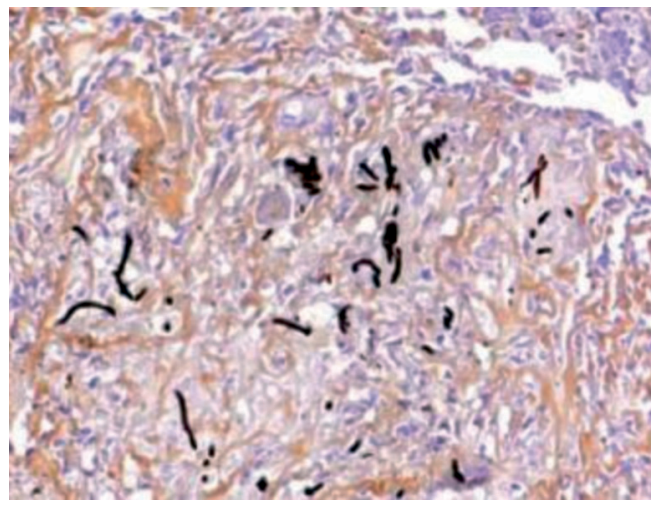

Fig 3. Septate hyphae of Aspergillus in necrotic tissue (silver stain $\times 400)$.

\section{Correspondence}

Josie Naomi lyeyasu

Rua Tenente Mauro de Miranda $96 / 102$ 04345-030 São Paulo SP - Brasil

E-mail: jobatatinha@yahoo.com.br

Received 12 July 2010

Received in final form 21 September 2010 Accepted 30 September 2010

\section{ASPERGILOSE INTRACRANIAL E ORBIAL EM UM PACIENTE IMUNOCOMPETENTE}

Clinics Hospital of the State University of Campinas, Faculty of Medical Sciences, Campinas SP, Brazil (HC-UNICAMP): ${ }^{1}$ Post-Graduation Student of the Department of Ophthalmo-Otolaryngology of the Clinics Hospital of the State University of Campinas, Faculty of Medical Sciences, Campinas SP, Brazil; ${ }^{2}$ Professor of the Department of Radiology of the Clinics Hospital of the State University of Campinas, Faculty of Medical Sciences, Campinas SP, Brazil; ${ }^{3}$ Professor of the Department of Pathology of the Clinics Hospital of the State University of Campinas, Faculty of Medical Sciences, Campinas SP, Brazil; ${ }^{4}$ Associate Professor and Chief of the Department of Ophthalmo-Otolaryngology of the Clinics Hospital of the State University of Campinas, Faculty of Medical Sciences, Campinas SP, Brazil. 